\title{
Genetic Disruption of Protein Kinase A Anchoring Reveals a Role for Compartmentalized Kinase Signaling in Theta-Burst Long-Term Potentiation and Spatial Memory
}

\author{
Ting Nie, ${ }^{1 \star}$ Conor B. McDonough, ${ }^{1 \star}$ Ted Huang, ${ }^{1 \star}$ Peter V. Nguyen, ${ }^{2}$ and Ted Abel ${ }^{1}$ \\ ${ }^{1}$ Department of Biology, University of Pennsylvania, Philadelphia, Pennsylvania 19104, and ${ }^{2}$ Departments of Physiology and Psychiatry, Centre for \\ Neuroscience, University of Alberta School of Medicine, Edmonton, Alberta, Canada T6G 2H7
}

\begin{abstract}
Studies of hippocampal long-term potentiation (LTP), a cellular model of memory storage, implicate cAMP-dependent protein kinase (PKA) in presynaptic and postsynaptic mechanisms of LTP. The anchoring of PKA to AKAPs (A kinase-anchoring proteins) creates compartmentalized pools of PKA, but the roles of presynaptically and postsynaptically anchored forms of PKA in late-phase LTP are unclear. In this study, we have created genetically modified mice that conditionally express $\mathrm{H} t 31$, an inhibitor of PKA anchoring, to probe the roles of anchored PKA in hippocampal LTP and spatial memory. Our findings show that at hippocampal Schaffer collateral CA3-CA1 synapses, theta-burst LTP requires presynaptically anchored PKA. In addition, a pool of anchored PKA in hippocampal area CA3 is required for spatial memory. These findings reveal a novel and significant role for anchored PKA signaling in cellular mechanisms underlying memory storage.
\end{abstract}

Key words: cAMP-dependent protein kinase; A kinase-anchoring proteins; hippocampus; spatial memory; synaptic plasticity; LTP

\section{Introduction}

Synaptic plasticity is a leading candidate mechanism for memory storage in the mammalian brain (Martin et al., 2000; Lynch, 2004). Long-term potentiation (LTP) in the hippocampus is a long-lasting increase in synaptic strength induced by highfrequency electrical stimulation that has been linked to specific types of hippocampus-dependent long-term memory (Abel et al., 1997; Gruart et al., 2006; Whitlock et al., 2006). cAMP-dependent protein kinase (PKA) has been implicated in presynaptic and postsynaptic mechanisms of LTP (for review, see Nguyen and Woo, 2003), but it is unclear whether presynaptic or postsynaptic PKA are differentially recruited for distinct forms of hippocampal LTP and long-term memory.

The idea that distinct pools of PKA exist follows the characterization of two isoforms of PKA, type I and type II (for review, see Skalhegg and Tasken, 2000), and the discovery of PKAanchoring proteins, known as A kinase-anchoring proteins (AKAPs), which compartmentalize PKA, placing it in the vicinity

\footnotetext{
Received April 10, 2007; revised Aug. 2, 2007; accepted Aug. 2, 2007.

This work was supported by the Human Frontiers Science Program (T.A.), the National Institutes of Health (T.A.), the University of Pennsylvania Provost's Distinguished International Scholars Program (P.V.N.), the Canadian Institutes of Health Research (P.V.N.), and the Alberta Heritage Foundation for Medical Research (P.V.N.). We thank Dr Jean Richa at the Transgenic and Chimeric Mouse Facility at the University of Pennsylvania for generating the Ht31 transgenic animals. We thank Dr. John Scott for providing the Ht31 cDNA clone, Dr. Mark Mayford for providing the CaMKII $\alpha$-tTA line B mice, and Dr. Nancy Bonini for the use of her fluorescence microscope. We also thank Dr. Philip Haydon, Dr. Cristina Alberini, and Noreen O'Connor-Abel for helpful discussions.

*T.N., C.B.M., and T.H. contributed equally to this work.

Correspondence should be addressed to Ted Abel at the above address. E-mail: abele@sas.upenn.edu.

T. Nie's present address: Department of Pharmacology, Emory University School of Medicine, Atlanta, GA 30322. D0I:10.1523/JNEUROSCI.1602-07.2007

Copyright $\odot 2007$ Society for Neuroscience 0270-6474/07/2710278-11\$15.00/0
}

of localized cAMP signals and target proteins (Smith and Scott, 2006). PKA anchoring is involved in the modulation of AMPA and NMDA receptors (Rosenmund et al., 1994; Westphal et al., 1999; Tavalin et al., 2002; Snyder et al., 2005). Given the complex cytoarchitectural features of neurons, spatial localization of intracellular signaling processes is especially critical. For example, the strength of subsets of synapses on a single neuron is believed to change independently of others (Frey and Morris, 1997) in a PKA-dependent manner (Young and Nguyen, 2005) even though synaptic plasticity engages diffusible second messenger systems such as calcium and cAMP (Lynch et al., 1983; Frey et al., 1993; Lynch, 2004). Anchoring PKA to AKAPs is one way that neurons may achieve localized PKA signaling in the face of diffusible cAMP, allowing for input-specific changes in synaptic strength.

PKA anchoring is required in the amygdala for fear conditioning (Moita et al., 2002) and for synaptic plasticity in cultured Aplysia neurons (Liu et al., 2004). Our work revealed that inputspecific LTP in area CA1 requires anchored PKA (Huang et al., 2006), but it is unclear whether this anchoring is required in neurons, whether this anchoring is presynaptic or postsynaptic, and whether an anchored pool of PKA is required for hippocampus-dependent spatial memory. Here, we examine the impact of genetic disruption of PKA-AKAP interactions on hippocampal synaptic plasticity and spatial memory using transgenic mice that conditionally express in forebrain neurons $\mathrm{Ht} 31$, a specific inhibitor of PKA anchoring. Our data show that at hippocampal Schaffer collateral CA3-CA1 synapses, theta-burst LTP selectively requires presynaptically anchored PKA, whereas LTP induced by multiple high-frequency trains requires postsynaptically anchored PKA. Furthermore, our data reveal that a pool 
of anchored PKA in CA3 neurons is selectively required for spatial memory storage. These data suggest a novel role for presynaptically anchored PKA in hippocampal synaptic plasticity, which correlates with a role for anchored PKA in CA3 neurons in spatial memory storage.

\section{Materials and Methods}

Transgenic mice. The Ht31 cDNA clone, which contains amino acids 418-718 of AKAP13 (AKAP-Lbc; GenBank accession number AF387101) (Klussmann et al., 2001), was kindly provided by Dr. John Scott (Vollum Institute, Oregon Health \& Science University, Portland, $\mathrm{OR}$ ). A fragment containing the $\mathrm{Ht} 31$ coding sequence was isolated by restriction digestion and ligated into plasmid MM400 (kindly provided by Dr. Mark Mayford, The Scripps Research Institute, La Jolla, CA) downstream of the tetO sequence (Mayford et al., 1996). AKAP-Lbc, from which the Ht31 cDNA was derived, has recently been shown to contain a binding site for the regulatory protein 14-3-3 near the binding site for the PKA regulatory subunits (Diviani et al., 2004). Sequence analysis of our $\mathrm{Ht} 31$ transgene fragment compared with that of AKAPLbc reveals that our transgene fragment does not contain this 14-3-3 binding site. The transgene fragment ( $\mathrm{Ht} 31 \mathrm{cDNA}$ flanked by promoter, intron, and exon sequences and polyadenylation sites) was isolated by NotI restriction digestion and purified by gel electrophoresis and Elutip-D columns (Schleicher and Schuell, Keene, NH). The purified fragment was microinjected into pronuclei of B6SJLF1/J zygotes, which were then implanted into pseudopregnant females at the Transgenic and Chimeric Animal Facility at the University of Pennsylvania. Positive founder animals were identified by Southern blot analysis, and resulting transgenic lines were backcrossed to C57BL/6J mice (The Jackson Laboratory, Bar Harbor, ME). TetO-Ht31 line 1 mice carry 34 copies of the transgene, whereas tetO-Ht31 line 16 mice carry nine copies of the transgene. The mice used in this study were at backcross generations 3-6 onto the C57BL/6J genetic background. To drive expression of Ht31, we crossed tetO-Ht31 transgenic mice to calcium/calmodulin dependent kinase II $\alpha(\mathrm{CaMKII} \alpha)$-tetracycline transcriptional activator protein (tTA) line B mice provided by Dr. Mark Mayford (The Scripps Research Institute) (Mayford et al., 1996). The CaMKII $\alpha$-tTA line B mice used in this study were at backcross generations $12-15$ onto the C57BL/6J genetic background. To shut off expression of the Ht31 transgene, we fed mice a diet containing doxycycline ( $200 \mathrm{mg} / \mathrm{kg}$; Bio-Serv, Frenchtown, NJ) for 2 weeks before and continuing through experimentation. In all experiments, Ht31 WT includes wild-type littermates from both lines of mice, whereas Ht31(1) WT and Ht31(16) WT refer to wild-type littermates from line 1 and line 16 mice, respectively.

All experiments were performed according to the National Institutes of Health guidelines and were fully approved by the Institutional Animal Care and Use Committee at the University of Pennsylvania.

In situ hybridization. The expression pattern of $\mathrm{Ht} 31$ in mice that carry both the tetO-driven $\mathrm{Ht} 31$ transgene and the CaMKII $\alpha$-tTA transgene were examined by in situ hybridization as described previously (Abel et al., 1997) using an $\left[\alpha^{-}{ }^{35} \mathrm{~S}\right]$ dATP-labeled oligonucleotide probe $\left(5^{\prime}-\right.$ CTCGGTTTATCGCCTGGGTCATTGGGCCTTGC- $3^{\prime}$ ) specific to the $\mathrm{Ht} 31$ transgene sequence. In situ images were scanned using a CCD camera (Cohu, San Diego, CA) and analyzed by ImageJ 1.37 software (NIH, Bethesda, MD). Three images were scanned per animal, and three measurements of pixel intensities from CA1, CA3, dentate gyrus (DG) and background were averaged from each image.

Immunoprecipitations. Hippocampi, cortex, and amygdalae from four mice were dissected, pooled by genotype, and homogenized in $150 \mu \mathrm{l}$ of non-denaturing lysis buffer ( $10 \mathrm{~mm}$ Tris $\mathrm{HCl}, \mathrm{pH}$ 7.05, $50 \mathrm{~mm} \mathrm{NaCl}, 30$ mu sodium pyrophosphate, $50 \mathrm{~mm} \mathrm{NaF,} 5 \mathrm{~mm} \mathrm{ZnCl}_{2}, 10 \%$ glycerol, and $0.5 \%$ Triton X-100). Protein concentration was quantified by Bradford assay (Bio-Rad, Hercules, CA) to normalize the total amount of protein in each lysate. The lysates (10 mg/sample) were incubated in $500 \mu \mathrm{l}$ of lysis buffer with $100 \mu \mathrm{l}$ of Protein G-Plus agarose beads (Invitrogen, Carlsbad, CA) and $10 \mu \mathrm{g}$ of RII antibody (Millipore, Billerica, MA) at $4^{\circ} \mathrm{C}$ overnight. Protein G-Plus beads were washed three times with lysis buffer. The immunoprecipitate was eluted using SDS-gel loading buffer
(50 mu Tris HCl, pH 6.8, 50 mm DTT, 1\% SDS, 0.005\% bromophenol blue, and $10 \%$ glycerol), separated by SDS-PAGE (12.5\% acrylamide gel), and visualized using Western blot analysis with anti-protein phosphatase 1 (PP1) antibody (1:1000; BD Biosciences Pharmingen, San Jose, CA), anti-RII antibody (1:1000; Millipore, Waltham, MA), and ECL detection reagents (GE Healthcare, Piscataway, NJ).

Peptides. Custom peptide synthesis of stearated Ht31 (StHt31) and Ht31P (StHt31P) was conducted by Quality Controlled Biochemicals (Hopkinton, MA). The sequences of the peptides were as follows: StHt31, St-N-DLIEEAASRIVDAVIEQVKAAGAY-C; StH31P, St-N-DLIEEAASRPVDAVPEQVKAAGAY-C (Vijayaraghavan et al., 1997). Peptides were delivered as lyophilized powder and resuspended at a stock concentration of $10 \mathrm{~mm}$ in $50 \mathrm{~mm}$ Tris- $\mathrm{HCl}, \mathrm{pH} 7.0$, and $0.05 \%$ DMSO to increase peptide solubility. Peptides were used at $10 \mu \mathrm{M}$ final concentration in artificial CSF (aCSF) in all experiments described.

Electrophysiology. Hippocampal slices were prepared as described previously (Abel et al., 1997). Briefly, 4- to 6-month-old male and female mice were killed by cervical dislocation, brains were removed, and hippocampi were rapidly dissected in chilled, oxygenated aCSF. Transverse hippocampal slices (400 $\mu \mathrm{m}$ thickness) were cut on a Stoelting (Wood Dale, IL) tissue slicer and placed in an interface recording chamber at $30^{\circ} \mathrm{C}$ (Fine Science Tools, Foster City, CA). Artificial CSF [(in mM) 124 $\mathrm{NaCl}, 4.4 \mathrm{KCl}, 1.3 \mathrm{MgSO}_{4}, 1 \mathrm{NaH}_{2} \mathrm{PO}_{4}, 26.2 \mathrm{NaHCO}_{3}, 2.5 \mathrm{CaCl}_{2}$, and 10 D-glucose bubbled with $95 \% \mathrm{O}_{2} / 5 \% \mathrm{CO}_{2}, \mathrm{pH} 7.4$ ] was constantly perfused over slices at a rate of $\sim 1 \mathrm{ml} / \mathrm{min}$. Slices were allowed to recover for $\sim 1.5 \mathrm{~h}$ before recording. Bipolar nichrome $(0.5 \mathrm{~mm}$; AM Systems, Carlsborg, WA) extracellular stimulating electrodes were positioned in stratum radiatum of CA1. Field EPSPs (fEPSPs) were recorded extracellularly using a glass micropipette (AM Systems) filled with aCSF with a resistance of 2-4 M $\Omega$. Data were acquired using Clampex 9.2 and a Digidata 1322 analog-to-digital converter (Molecular Devices, Union City, CA) at $20 \mathrm{kHz}$ and were low-pass filtered at $2 \mathrm{kHz}$ with a four-pole Bessel filter. To examine basal synaptic transmission, we constructed input-output curves by measuring the initial slope of the fEPSP in response to gradual increases in the strength of the stimulus. Slices that had maximum amplitude responses of $<4 \mathrm{mV}$ were rejected. The stimulus strength was then set to elicit $40 \%$ of the maximum fEPSP amplitude. Paired-pulse facilitation (PPF) was then examined at various interpulse intervals (25-300 ms). For LTP experiments, test pulses were delivered to Schaffer collaterals once every minute for $20 \mathrm{~min}$ to record baseline responses. After $20 \mathrm{~min}$, LTP was induced electrically using one of several protocols. A four-train (four $1 \mathrm{~s}, 100 \mathrm{~Hz}$ trains delivered 5 min apart), theta-burst (15 bursts of four $100 \mathrm{~Hz}$ pulses spaced $200 \mathrm{~ms}$ apart), or onetrain stimulus (one $1 \mathrm{~s}, 100 \mathrm{~Hz}$ train of pulses) was used to induce LTP. Long-term depression (LTD) was induced by delivering 900 pulses at $1 \mathrm{~Hz}$ to the Schaffer collaterals. For the analysis of fEPSPs during theta-burst stimulation, the area encompassed by each burst of fEPSPs was measured by integrating the area between the four fEPSP traces and baseline and was normalized to the area of the first burst (Schmitt et al., 2005). After induction of synaptic potentiation or depression, test pulses were delivered once per minute for $2 \mathrm{~h}$, or $1 \mathrm{~h}$ in the case of the one-train and LTD experiments. In some experiments, a PKA inhibitor KT5720 (Sigma-Aldrich, St. Louis, MO) was included in the aCSF at a concentration of $1 \mu \mathrm{M}$. In experiments involving pharmacological reagents, StHt31, StHt31P, or KT5720 were applied from $15 \mathrm{~min}$ before induction until $15 \mathrm{~min}$ after LTP or LTD induction. In some four-train and theta-burst LTP experiments, PPF at 50 and $100 \mathrm{~ms}$ interpulse intervals was measured every $15 \mathrm{~min}$ throughout the duration of the LTP recordings. In experiments involving transgenic mice, the electrophysiological data were represented as $n=$ number of mice for each genetic manipulation. In experiments involving pharmacological treatment, the data were represented as $n=$ number of treatments.

Morris water maze. Training and testing in the hidden-platform version of the water maze were performed as described previously (Lattal et al., 2003). Mice in this study were 2-3 months of age, trained with 2 trials/d (5 min intertrial interval) for $7 \mathrm{~d}$. Escape latency, quadrant preference, and platform-crossing data were acquired by the Water 2020 tracking program (HVS Image, Buckingham, UK). In the probe test on day 8 , the platform was not present. During the probe trial, the percentage of time in each of the four quadrants and the number of platform 
crosses were measured to assess spatial memory. In the visible platform version of the water maze, the distal cues from the original training room were removed, and the platform was cued by a marker extending from the center of the platform above the surface of the water (Lattal et al., 2003). The position of the platform was changed each day. Mice were trained with 2 trials/d, and the escape latency was measured. Naive mice were used in the visible platform experiment in the Morris water maze. Naive mice were treated with doxycycline to examine the effects of shutting off $\mathrm{Ht} 31$ expression on spatial learning and memory. In the water maze experiment involving doxycycline, mice were fed diet containing $200 \mathrm{mg} / \mathrm{kg}$ doxycycline for 2 weeks before the start of the experiment and remained on the same doxycycline diet throughout the duration of the experiment.

Data analysis. Data analysis was performed using SigmaStat 3.5 software (Systat Software, San Jose, CA) and Statistica 7.1 software (Statsoft, Tulsa, OK). In situ hybridization data were analyzed by Student's $t$ tests. Behavioral data were analyzed by ANOVA and post hoc Tukey-Kramer tests. Electrophysiological data examining basal synaptic transmission were analyzed by parametric tests because each dataset passed tests of normality and displayed equal variance. The ratios of the fEPSP slopes to presynaptic fiber volleys were averaged within each animal and analyzed by one-way repeated-measures ANOVA. The slopes of the maximum fEPSPs during input-output tests were averaged within each animal and analyzed by one-way repeated-measures ANOVA. Paired-pulse facilitation data are presented as the ratios of the responses elicited by the second stimuli to the responses elicited by the first stimuli and were first averaged within each animal and then analyzed by two-way repeated-measures ANOVA.

Electrophysiological data from LTP and LTD recordings were analyzed by nonparametric tests because our data were not consistently normally distributed and the analyses of repetitive recordings over long durations do not allow the use of parametric tests (Sajikumar et al., 2007). The initial slope of the fEPSP at each time point was analyzed. For comparisons between two groups, the Mann-Whitney $U$ test was used. Differences were considered statistically significant when $p<0.05$. For comparisons between multiple groups, the Kruskal-Wallis one-way ANOVA was first used, and for time points at which groups were different $(p<0.05)$, the Mann-Whitney $U$ test was used. Differences were considered statistically significant only when $p<0.05$ in Kruskal-Wallis and the post hoc tests. The areal measurements for bursts of fEPSPs during theta-burst stimulation were compared using the Mann-Whitney $U$ test.

\section{Results}

Transgenic expression of Ht31 disrupts PKA-AKAP

interactions but does not alter PKA activity

To examine the role of PKA anchoring in spatial learning and hippocampal synaptic plasticity, we generated transgenic mice expressing a fragment (amino acids 418-718) of Ht31 (GenBank accession number AF387101), a truncated transcript of the naturally occurring human thyroid AKAP-Lbc (GenBank accession number AF406992) (Klussmann et al., 2001; Diviani et al., 2004). $\mathrm{Ht} 31$ has been used to examine the role of PKA anchoring in numerous biological processes, such as neurotransmitter receptor modulation, insulin secretion, sperm motility, and cardiac myocyte contractility (Rosenmund et al., 1994; Lester et al., 1997; Vijayaraghavan et al., 1997; Westphal et al., 1999; Fink et al., 2001; Tavalin et al., 2002; Snyder et al., 2005). The transgene fragment retains the PKA regulatory subunit-binding domain but lacks the N-terminal membrane-targeting domain, thereby effectively mislocalizing PKA without altering kinase activity (Lester et al., 1997). This transgene is expressed under the control of the tetracycline transactivator system (Fig. 1). In this system, a tetracycline transcriptional activator protein, referred to as tTA, is expressed from the CaMKII $\alpha$ promoter in forebrain neurons (Mayford et al., 1996). CaMKII-tTA line B [tTA(B)] mice are crossed to two different lines of $\mathrm{Ht} 31$ transgenic animals, tetO- a
$\mathrm{Tg}-1$ : tTA in forebrain neuron
Tg-2: No expression

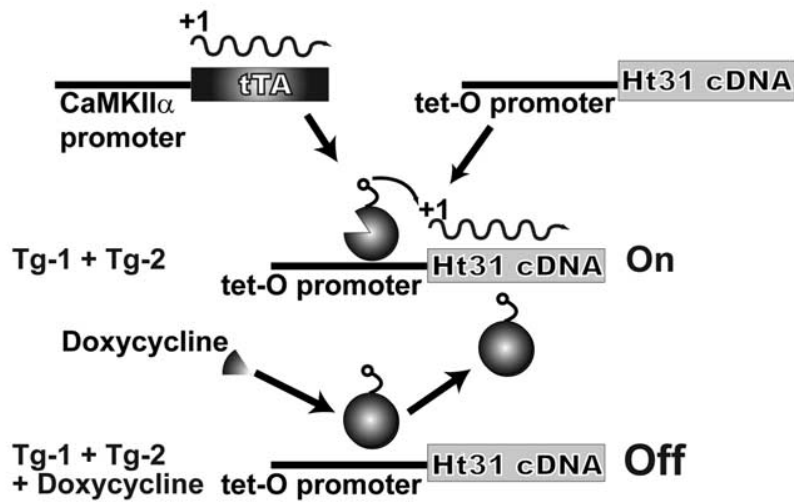

b

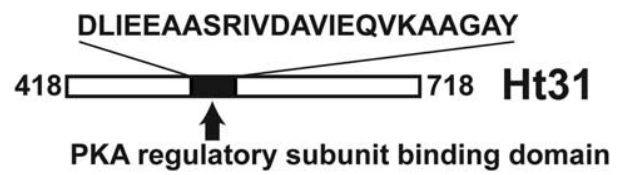

C $\stackrel{*}{*} \stackrel{*}{*}$ stearyI-DLIEEAASRIVDAVIEQVKAAGAY stHt31 peptide
stearyI-DLIEEAASRPVDAVPEQVKAAGAY stHt31P peptide

Figure 1. Genetic and pharmacological strategies for disrupting PKA-AKAP interactions. $\boldsymbol{a}$, We generated transgenic mice carrying a tet0- $\mathrm{Ht} 31$ transgene $(\mathrm{Tg}-2)$ and crossed these mice to CaMKIl $\alpha$-tTA line B transgenic mice ( $\mathrm{Tg}-1$ ). In bigenic mice carrying both transgenes, tTA binds to the tetracycline-responsive promoter (tet0) and initiates transcription of the Ht 31 transgene. Because the CaMKII $\alpha$ promoter is expressed in forebrain neurons, tTA expression (and thus the expression of $\mathrm{Ht} 31$ ) is limited to neurons within the mouse forebrain. Treatment with doxycycline blocks the binding of tTA to the tet 0 promoter and thus suppresses Ht 31 expression. $\boldsymbol{b}$, The Ht31 cDNA encodes a truncated version (amino acids 418-718) of the naturally occurring human thyroid AKAP-Lbc containing a high-affinity binding site for the type II PKA regulatory subunit. c, Synthetic $\mathrm{Ht} 31$ peptide made membrane permeable by the addition of an N-terminal stearyl group (StHt31) corresponds to the PKA regulatory subunit-binding domain of the $\mathrm{Ht} 31$ transgene product. An inactive control peptide, StHt31P, contains proline substitutions (indicated by asterisks) that prevent the binding of the peptide to PKA regulatory subunits.

Ht31 line 1 and tetO-Ht31 line 16, that carry the Ht31 transgene driven by a tetracycline-responsive promoter (Fig. 1a). Bigenic offspring resulting from this cross carry both the CaMKII-tTA and tetO-Ht31 transgenes, selectively driving expression of $\mathrm{Ht} 31$ in forebrain neurons. These bigenic mice carrying tTA(B) and tetO-Ht31 transgenes are referred to as $\mathrm{Ht} 31$ transgenic mice. We refer to bigenic tetO-Ht31 line 1 animals as Ht31(1) mice, and we refer to bigenic tetO-Ht31 line 16 animals as $\mathrm{Ht31}$ (16) mice. $\mathrm{Ht} 31$ (1) and Ht31(16) mice were found to express Ht31 in several forebrain regions, including the hippocampus and cortex, by in situ hybridization using a probe specific to the Ht31 transgene (Fig. 2a). The expression of the Ht31 transgene can be suppressed in both Ht31(1) and Ht31(16) mice by treatment with $200 \mathrm{mg} / \mathrm{kg}$ doxycycline in the mouse diet for 2 weeks (Fig. 2a). Interestingly, we observed that the level of Ht31 mRNA detected in hippocampal area CA3 of Ht31 line 1 mice was higher than that detected in hippocampal area CA3 of Ht31 line 16 mice (Fig. 2b). An assessment of the expression levels of Ht31 in CA1, CA3, and DG in both lines revealed a greatly reduced expression of $\mathrm{Ht} 31$ in $\mathrm{CA} 3$ in Ht31(16) animals relative to $\mathrm{Ht31}$ (1) animals (Fig. 2c). After background subtraction and normalization, the mean pixel in- 
a
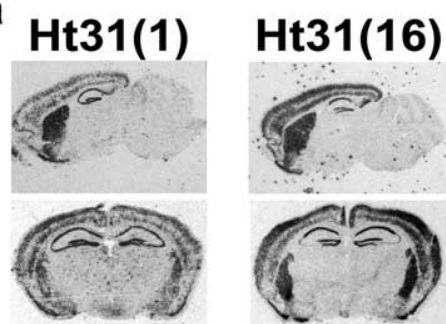

Ht31(1) Dox Ht31(16) Dox

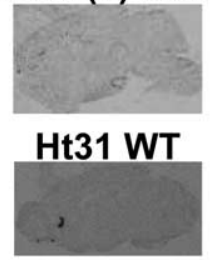

b

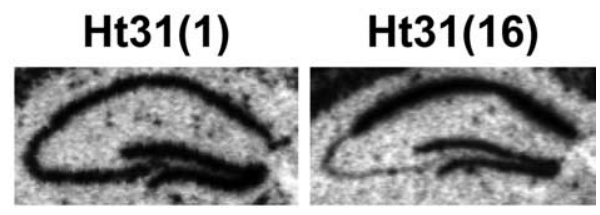

C

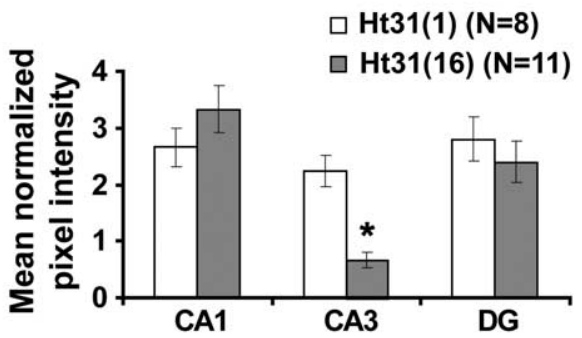

d
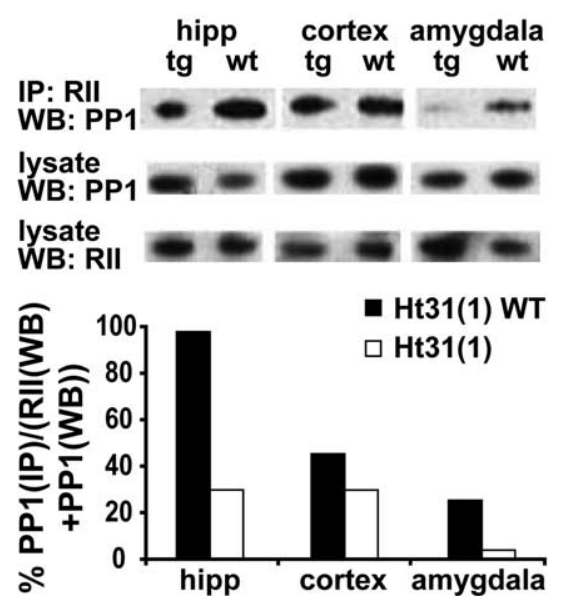

$\mathrm{Ht} 31(1)$
$\mathrm{Ht} 31$ (16)

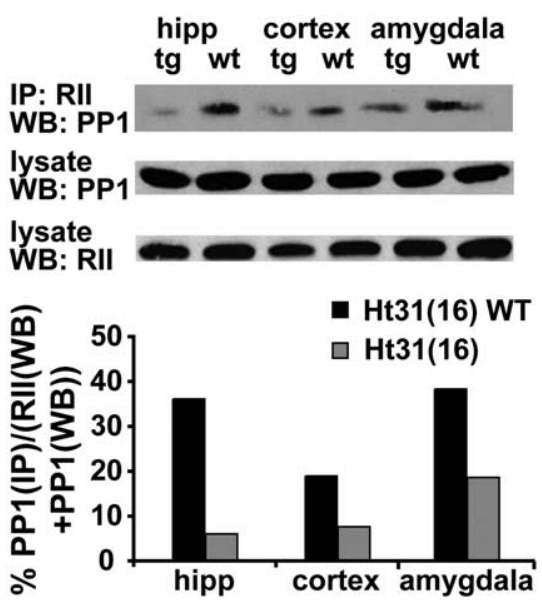

Figure 2. Transgenic expression of $\mathrm{Ht} 31$ blocks the formation of AKAP complexes. $\boldsymbol{a}$, Representative sagittal and coronal in situ hybridizations demonstrating that both lines of $\mathrm{Ht} 31$ transgenic mice carrying the tet 0 - $\mathrm{Ht} 31$ and $\mathrm{CaMKII} \alpha$ - $\mathrm{tTA}$ transgenes express $\mathrm{Ht} 31$ in the hippocampus, cortex, striatum, and amygdala. No expression was detected in wild-type littermates or in $\mathrm{Ht} 31$ transgenic animals treated with doxycycline (Dox). No Ht31 expression was seen in mice carrying only the tet0-Ht31 transgene (data not shown). $\boldsymbol{b}$, Representative in situ hybridizations demonstrating differences in expression of the $\mathrm{Ht} 31$ transgene in hippocampal area CA3 between $\mathrm{Ht} 31(1)$ and $\mathrm{Ht} 31$ (16) animals. The levels of $\mathrm{Ht} 31$ detected in CA1, DG, and extrahippocampal areas were similar in these two lines. $c$, A comparison of the relative levels of $\mathrm{Ht} 31 \mathrm{mRNA}$ from in situ hybridization indicates similar expression levels of the transgene in CA1 and DG in both lines of $\mathrm{Ht} 31$ transgenic mice. However, transgene expression was significantly reduced $\left({ }^{*} p<0.001\right)$ in CA3 of Ht31(16) mice. Error bars represent SEM. $\boldsymbol{d}$, Reduced expression levels of PP1 were found in immunoprecipitations (IP) using antibodies against RII on brain extracts from the hippocampus (hipp), cortex, and amygdala from $\mathrm{Ht} 31$ transgenic mice (tg) relative to wild-type littermates (top and quantified below), indicating that $\mathrm{Ht} 31$ effectively disrupts AKAP complexes in these transgenic mice. Western blotting (WB) of brain lysates revealed that PP1 and RII levels were similar between $\mathrm{Ht} 31$ transgenic mice and wild-type littermates.

tensities in CA1 regions [Ht31(1), $2.67 \pm 0.34 ; \mathrm{Ht} 31(16), 3.33 \pm$ $0.41]$ and DG [Ht31(1), $2.80 \pm 0.39 ; \mathrm{Ht} 31(16), 2.40 \pm 0.37]$ were not significantly different between the two lines (Student's $t$ test, $p$ values $>0.1)$. However, the mean pixel intensities in CA3 [Ht31(1), $2.24 \pm 0.29 ; \mathrm{Ht} 31(16), 0.67 \pm 0.13]$ were significantly different between the two lines, with levels in line 1 over three times greater than those in line 16 (Student's $t$ test, $p<0.001$ ). We observed no gross alterations in brain morphology in $\mathrm{Ht} 31$ (1) or Ht31(16) transgenic mice relative to wild-type littermates using cresyl violet staining (data not shown), immunostaining against MAP2 (microtubule-associated protein 2; a marker of neuronal cell bodies and dendrites) (data not shown), or in situ hybridization (Fig. 2a).

To determine whether expression of Ht31 disrupts AKAP complexes containing PKA, we performed immunoprecipitation experiments. Antibodies against PKA-type II regulatory subunits were used to precipitate protein complexes from extracts prepared from Ht31(1) and Ht31(16) transgenic mice and wild-type littermates. Using antibodies to PP1, one of the phosphatases found in PKA-AKAP complexes (Westphal et al., 1999), we determined that lower levels of PP1 were present in RII immunoprecipitates from Ht31(1) and Ht31(16) transgenic mice relative to wild-type littermates (Fig. $2 d$ ). Overall levels of PP1 and RII in extracts from Ht31(1) and Ht31(16) transgenic mice and wild-type littermates were similar (Fig. $2 d$ ). We also examined PKA activity in extracts prepared from the hippocampus and amygdala using methods described previously (Abel et al., 1997). No significant differences in PKA activity were found between transgenics and controls in either the hippocampus or amygdala (data not shown). Thus, the expression of Ht31 in neurons disrupts AKAP complexes but does not alter basal PKA activity.

Basal synaptic transmission is normal in Ht31 transgenic mice

We found that basal synaptic transmission at Schaffer collateral-CA1 synapses was normal in $\mathrm{Ht} 31$ transgenic mice relative to their wild-type littermates. Input-output curves relating presynaptic fiber volley amplitude to the initial slope of the corresponding fEPSP were not different between $\mathrm{Ht} 31$ transgenic mice and wild-type littermates (Fig. 3a) (one-way ANOVA, $\left.F_{(2,21)}=1.51 ; p>0.05\right)$. The maximum fEPSP slopes [WT, $-6.45 \pm 0.53 \mathrm{mV} / \mathrm{ms}$; $\mathrm{Ht} 31(1),-6.48 \pm 0.25 \mathrm{mV} / \mathrm{ms}$; Ht31(16), $-6.41 \pm 0.57 \mathrm{mV} / \mathrm{ms}]$ were not significantly different across genotypes (oneway ANOVA, $\left.F_{(2,57)}=0.002 ; p>0.05\right)$. Additionally, PPF, an enhancement in response to the second of two closely spaced stimuli, did not differ significantly between slices from Ht31 transgenic mice and wild-type littermates across various interpulse intervals ranging from 25 to $300 \mathrm{~ms}$ (two-way repeated-measures ANOVA, $\left.F_{(8,154)}=0.645 ; p>0.05\right)$ (Fig. $3 c$ ). These results are consistent with data from our previous study, in which acute application of membrane-permeant $\mathrm{Ht} 31$ peptide (StHt31) did not affect basal synaptic function (Huang et al., 2006).

Genetic and pharmacological disruption of PKA anchoring impairs long-lasting forms of hippocampal LTP

We have previously observed that treatment of hippocampal slices with membrane-permeant Ht31 peptide impairs PKAdependent hippocampal late-phase LTP (L-LTP) (Huang et al., 2006). However, this treatment affects all cells within the slice, 
making it impossible to define the specific role of PKA anchoring in hippocampal L-LTP in excitatory neurons. Here, we tested directly the effects of disrupting PKA anchoring in hippocampal neurons using genetically modified mice that express $\mathrm{Ht} 31$ only in excitatory neurons. Because Ht31(1) mice express Ht31 in CA3, but Ht31(16) mice show much lower expression of $\mathrm{Ht} 31$ in this region, we were able to examine the effects of disrupting presynaptic PKA anchoring in different forms of hippocampal LTP at the CA3CA1 synapse.

At least two different forms of LTP exist in hippocampal area CA1: early-phase LTP (E-LTP) and L-LTP (Frey et al., 1988; Matthies et al., 1990; Nguyen and Woo, 2003; Reymann and Frey, 2007). E-LTP is induced using brief electrical stimuli (typically a single $1 \mathrm{~s}, 100 \mathrm{~Hz}$ train of stimuli), lasts $1-2 \mathrm{~h}$ in hippocampal slices, and requires calcium influx through NMDA receptors and activation of downstream targets such as CaMKII $\alpha$ (Malenka and Nicoll, 1999), but does not require PKA or de novo protein synthesis (Frey et al., 1988, 1993; Huang and Kandel, 1994). In contrast, L-LTP is induced using repeated trains of electrical stimuli (typically either four $1 \mathrm{~s}, 100 \mathrm{~Hz}$ trains of electrical stimuli or theta-burst stimuli), lasts for several hours in vitro to days in vivo, and requires NMDA receptor activation, transcription, and protein synthesis, as well as PKA (Frey et al., 1988; Nguyen et al., 1994; Abel et al., 1997; Nguyen and Woo, 2003). L-LTP shares many features of long-term memory in the hippocampus, such as requirements for protein synthesis, transcription, and PKA activity.

We found that hippocampal L-LTP at Schaffer collateral-CA1 synapses induced by four $1 \mathrm{~s}, 100 \mathrm{~Hz}$ trains of electrical stimuli was impaired in slices from both lines of Ht31 transgenic mice relative to slices from wild-type littermates (Kruskal-Wallis ANOVA, $p<0.05$ ) (Fig. 4a). The mean fEPSP slopes at $2 \mathrm{~h}$ after the induction of L-LTP were significantly different between wildtype littermates $(202 \pm 17 \%)$ and $\mathrm{Ht} 31$ mice $[\mathrm{Ht} 31(1), 117 \pm$ 14\%; Ht31(16), $114 \pm 16 \%$ ] (Mann-Whitney $U$ test, $p<0.05$ ). These differences began at $\sim 60$ min after the last tetanus (MannWhitney $U$ tests, $p<0.05$ ). Both male and female mice exhibited these differences; thus, data from both sexes were included in the analysis (supplemental Fig. 1, available at www.jneurosci.org as supplemental material). Impairment of this form of LTP in $\mathrm{Ht} 31$ (16) mice suggests that postsynaptic disruption of PKA anchoring is sufficient to disrupt four-train L-LTP. The deficits in four-train L-LTP were reversed when $\mathrm{Ht} 31$ transgene expression was suppressed by treatment with doxycycline $(200 \mathrm{mg} / \mathrm{kg}$ in the mouse diet for 2 weeks) (Kruskal-Wallis ANOVA, $p>0.05$ ), indicating that these deficits were not attributable to developmental or compensatory effects (Fig. $4 b$ ).

E-LTP elicited by one $1 \mathrm{~s}, 100 \mathrm{~Hz}$ train was not different between slices from $\mathrm{Ht31(1)}$ and $\mathrm{Ht} 31$ (16) transgenic mice and slices from wild-type mice (Kruskal-Wallis ANOVA, $p>0.05$ ) (Fig. 4c). We also examined whether a form of LTD induced by 15 min of low-frequency electrical stimulation was impaired in $\mathrm{Ht} 31$

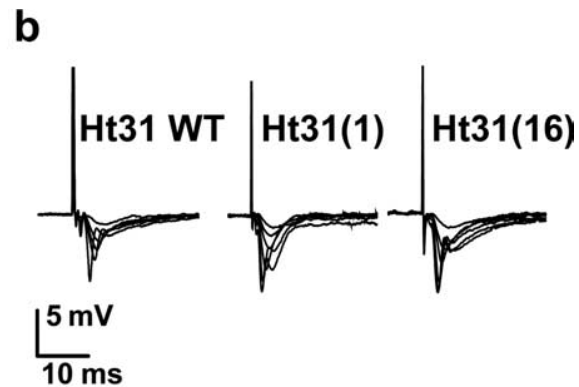

d
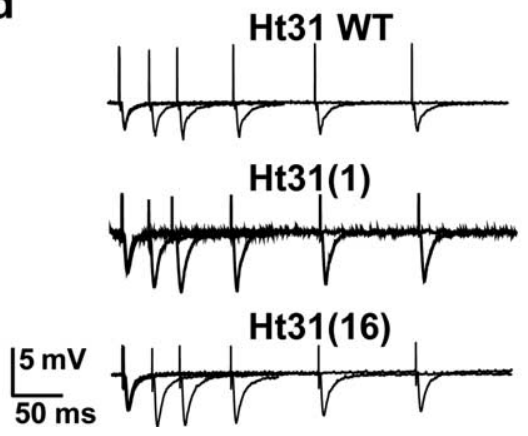

- Ht31 WT ( $\mathrm{N}=9)$ $\square \mathrm{Ht} 31(1)(\mathrm{N}=7)$ $\diamond \mathrm{Ht} 31(16)(\mathrm{N}=6)$

$\mathrm{m} \mathrm{H} 31$ transgenic mice. $\boldsymbol{a}$, Input-output curves relating the amplitude of the presynaptic fiber volley to the initial slope of the corresponding fEPSP at various stimulus intensities revealed no differences between slices from $\mathrm{Ht} 31$ transgenic mice and wild-type littermates $(p>0.05)$. $\boldsymbol{b}$, Sample sweeps at various stimulus intensities acquired from slices from $\mathrm{Ht} 31(1)$ and $\mathrm{Ht} 31(16)$ transgenic and wild-type littermates. $c_{\text {, }}$ different between slices from $\mathrm{Ht} 31$ transgenic mice and wild-type littermates ( $p>0.05$ ). Error bars represent SEM. $\boldsymbol{d}$, Sample sweeps acquired at various interpulse intervals in slices from $\mathrm{Ht} 31$ transgenic mice and wild-type littermates.

transgenic mice. We observed that hippocampal slices from Ht31 transgenic animals displayed normal LTD relative to wild-type littermates (Kruskal-Wallis ANOVA, $p>0.05$ ) (Fig. 4d).

When we examined theta-burst L-LTP (four $100 \mathrm{~Hz}$ pulses delivered in bursts that are $200 \mathrm{~ms}$ apart for a total of $3 \mathrm{~s}$ ), we observed impairments in slices from Ht31(1) mice but not in slices from $\mathrm{Ht} 31$ (16) mice, relative to slices from wild-type littermates (Kruskal-Wallis ANOVA, $p<0.05$ ) (Fig. 5a). Two hours after the induction of LTP, the mean fEPSP slopes from wild-type littermates $(169 \pm 10 \%)$ and Ht31(16) mice $(162 \pm 13 \%)$ were significantly different from the mean fEPSP slope from Ht31(1) mice $(110 \pm 7 \%)$ (Mann-Whitney $U$ tests, $p<0.05)$. These differences began at $\sim 75 \mathrm{~min}$ after the induction of theta-burst L-LTP (Mann-Whitney $U$ tests, $p<0.05$ ). Both male and female mice exhibited these differences; thus, data from both sexes were included in the analysis (supplemental Fig. 1, available at www.jneurosci.org as supplemental material). This deficit in thetaburst L-LTP was reversed when $\mathrm{Ht} 31$ transgene expression was suppressed by treatment with doxycycline $(200 \mathrm{mg} / \mathrm{kg}$ in the mouse diet for 2 weeks), indicating that this deficit was not caused by developmental or compensatory effects (Mann-Whitney $U$ tests, $p>0.05$ ) (Fig. $5 c$ ). Because Ht31(1) mice express $\mathrm{Ht} 31$ in CA3, the deficits in theta-burst L-LTP in these mice suggest that presynaptic anchoring of PKA is required for thetaburst L-LTP. To determine whether pharmacological blockade of PKA anchoring impaired theta-burst L-LTP, we treated wildtype slices with the cell-permeable PKA-anchoring inhibitory peptide StHt31 (Vijayaraghavan et al., 1997). Wild-type slices treated with StHt31 peptide $(10 \mu \mathrm{M})$ showed similar deficits in theta-burst L-LTP compared with slices treated with the inactive 
a
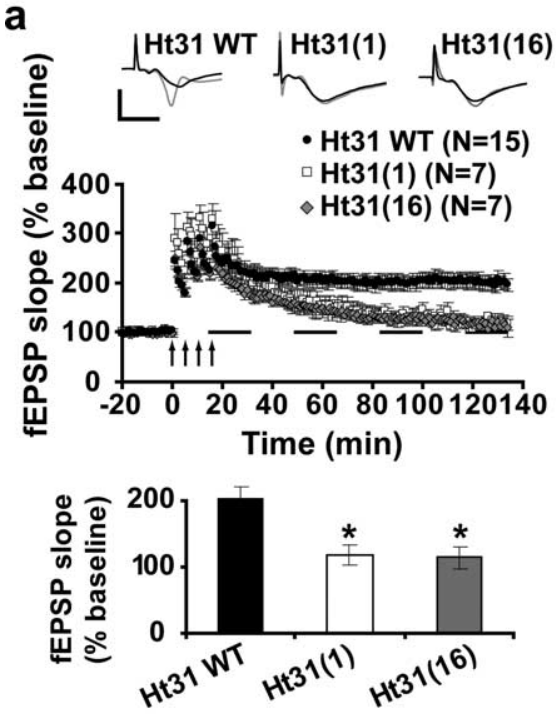

C
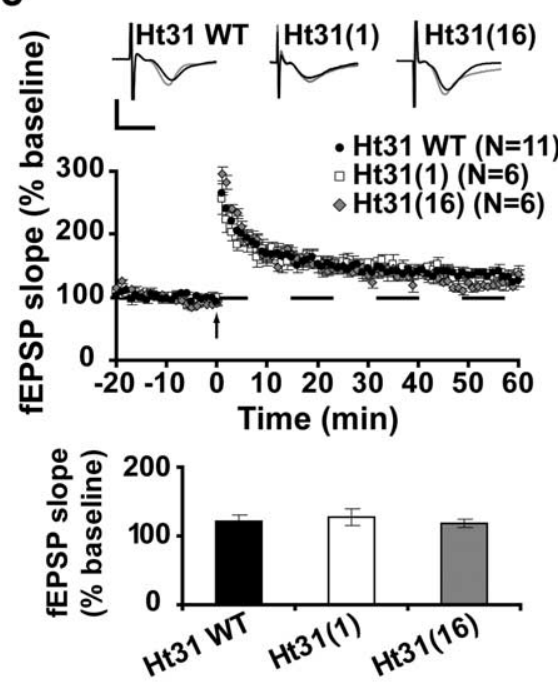

b
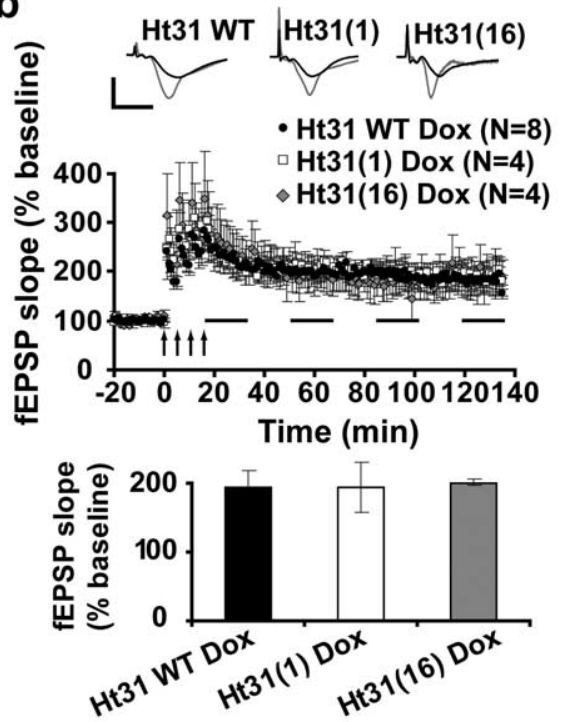

d
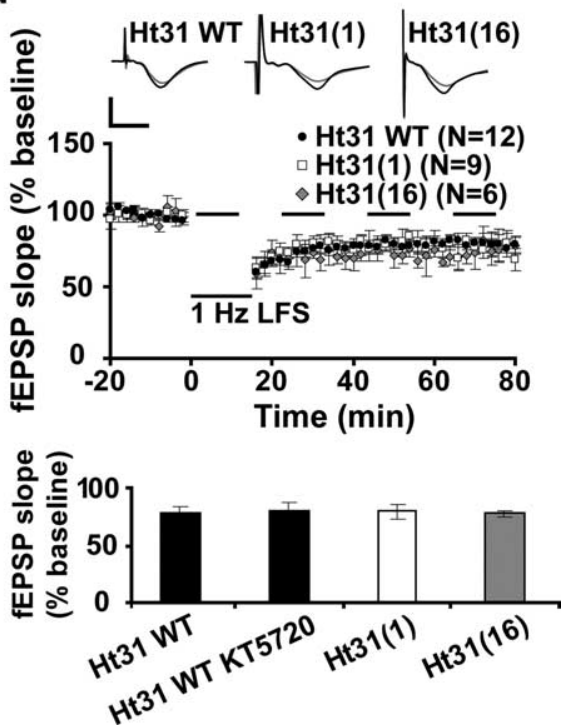

Figure 4. The requirement for PKA anchoring is limited to long-lasting forms of PKA-dependent hippocampal LTP. $\boldsymbol{a}$, Hippocampal L-LTP induced by four $1 \mathrm{~s}, 100 \mathrm{~Hz}$ trains of electrical stimuli (arrows) is impaired in slices from $\mathrm{Ht} 31$ transgenic mice relative to slices from wild-type littermates ( post hoc analysis, ${ }^{*} p<0.05$ ). The deficit in four-train LTP observed in Ht31(16) transgenic mice indicates that this form of LTP requires postsynaptic PKA anchoring. The bar graph indicates mean normalized fEPSP slopes at $2 \mathrm{~h}$ after tetanus. $\boldsymbol{b}$, The deficit in four-train LTP was abolished when $\mathrm{Ht} 31$ transgene expression was suppressed by administration of $200 \mathrm{mg} / \mathrm{kg}$ doxycycline in the diet $(p>0.05)$, demonstrating that this deficit resulted from expression of the $\mathrm{Ht} 31$ transgene. The bar graph indicates mean normalized fEPSP slopes at $2 \mathrm{~h}$ after tetanus. $c$, A more transient form of LTP, induced by a single $1 \mathrm{~s}, 100 \mathrm{~Hz}$ train, which does not require PKA activity, was not altered by Ht31 expression $(p>0.05)$. The bar graph indicates mean normalized fEPSP slopes at $1 \mathrm{~h}$ after tetanus. $\boldsymbol{d}$, Long-term depression induced by $15 \mathrm{~min}$ of $1 \mathrm{~Hz}$ electrical stimuli was not impaired by expression of $\mathrm{Ht} 31$ ( $p>0.05$ ). The bar graph indicates mean normalized fEPSP slopes at $1 \mathrm{~h}$ after induction. This form of LTD was unaffected by KT5720 (see bar graph). In all sample sweeps, black traces indicate baseline, and gray traces were acquired at $\sim 2 \mathrm{~h}$ after tetanus (for $\boldsymbol{a}, \boldsymbol{b}$ ) or $1 \mathrm{~h}$ after tetanus (for $\boldsymbol{c}, \boldsymbol{d}$ ). Calibration: $5 \mathrm{mV}, 5 \mathrm{~ms}$. LFS, Low-frequency stimulation. Dashed lines indicate baseline. Error bars represent SEM.

control StHt31P peptide (Fig. $5 d$ ). Two hours after the induction of LTP, the mean fEPSP slope from StHt31P-treated slices $(187.0 \pm 17 \%)$ was significantly different from the mean fEPSP slope from StHt31-treated slices (105 $\pm 5 \%$ ) (Mann-Whitney $U$ tests, $p<0.05)$. These differences emerged $\sim 75 \mathrm{~min}$ after the induction of theta-burst L-LTP (Mann-Whitney $U$ tests, $p<$ 0.05). The intact theta-burst L-LTP in Ht31(16) transgenic mice required PKA, because treatment with a PKA inhibitor KT5720 impaired theta-burst L-LTP in Ht31(16) transgenic mice (Kruskal-Wallis ANOVA, $p<0.05$ ) (Fig. 5b).

To determine whether inhibition of PKA anchoring alters normal dendritic field responses to theta-burst stimulation, we examined the areas encompassed by bursts of fEPSPs (Fig. 5e), as well as slopes of individual fEPSPs (data not shown), during theta-burst stimulations. These measurements were not different between StHt31- or StHt31P-treated slices (MannWhitney $U$ tests, $p>0.05$ ) (Fig. 5e). Similarly, there is no significant difference between transgenic groups and wild-type littermates in their dendritic field responses to theta-burst stimulation (data not shown). These findings suggest that disruption of PKA anchoring does not significantly alter transmitter release during theta-burst stimulation. Nevertheless, changes in the probability of presynaptic transmitter release may contribute to LTP (Schulz et al., 1994). Also, chemical activation of the cAMPPKA pathway enhances transmitter release presynaptically (Bolshakov et al., 1997). PPF provides a measure of changes in the probability of presynaptic release (Schulz et al., 1994, 1995). To determine whether the theta-burst L-LTP impairment in Ht31(1) mice involved a presynaptic component, we measured PPF at $50 \mathrm{~ms}$ (Fig. 5f) and $100 \mathrm{~ms}$ (data not shown) interpulse intervals before and after the induction of theta-burst L-LTP. A decrease in PPF would suggest an increase in the probability of presynaptic transmitter release. Shortly after theta-burst stimulation, PPF was reduced by $\sim 15 \%$ compared with pre-LTP levels in all groups of mice. For wildtype littermates and Ht31(16) mice, PPF remained reduced throughout the duration of the L-LTP recording. In contrast, PPF returned toward baseline levels in $\mathrm{Ht} 31$ (1) mice for both 50 and $100 \mathrm{~ms}$ interpulse intervals (Kruskal-Wallis ANOVA, $p<0.05)$. Two hours after the induction of LTP, the normalized PPF values from wild-type littermates $(50 \mathrm{~ms}$ PPF, 87.5 \pm 3\%; $100 \mathrm{~ms}$ PPF, $87.9 \pm$ $3 \%)$ and $\mathrm{Ht} 31(16)$ mice $(87.3 \pm 3 \%$; $89.9 \pm 3 \%$ ) were significantly different from normalized PPF values from Ht31(1) mice $(97.5 \pm 2 \%$; $98.5 \pm 2 \%)$ (Mann-Whitney $U$ tests, $p<0.05)$. In contrast to theta-burst stimulation that induced lasting reduction in PPF in slices from wild-type littermates, four $100 \mathrm{~Hz}$ trains of electrical stimuli induced a transient reduction in PPF (data not shown), consistent with previous reports in wild-type mice demonstrating only transient decrease in PPF after LTP induction with four trains of high-frequency stimulation (Duffy and Nguyen, 2003). 
Ht31 expression in CA3 is specifically associated with memory impairments in the spatial version of the Morris water maze

We tested Ht31 transgenic mice in spatial learning using the hidden-platform version of the Morris water maze, a hippocampus-dependent learning task (Schenk and Morris, 1985). During training for this task, mice learn to locate a hidden platform using distal environmental cues. We trained Ht31 transgenic and wild-type control mice with 2 trials/d for 7 consecutive days. Swimming speed and thigmotaxis (data not shown) were not different between $\mathrm{Ht} 31$ transgenic mice and wild-type littermates. There was no interaction between sex, genotype, and acquisition latency (three-way repeatedmeasures ANOVA, $F_{(12,324)}=1.01 ; p>$ 0.05 ), quadrant preference (three-way repeated-measures ANOVA, $F_{(6,162)}=$ $1.92 ; p>0.05)$, or platform crossing (three-way repeated-measures ANOVA, $\left.F_{(6,177)}=0.91 ; p>0.05\right)$. There was no main effect of sex on any of these measures. Furthermore, female and male transgenic mice and wild-type littermates displayed similar quadrant preferences during the probe trial (supplemental Fig. 1, available at www.jneurosci.org as supplemental material). Thus, data from both sexes were included in the analysis. Both $\mathrm{Ht} 31$ (1) and Ht31(16) transgenic mouse lines were impaired in the acquisition of a spatial preference (two-way repeatedmeasures ANOVA, $F_{(2,342)}=5.30 ; p<$ 0.01 ; post hoc Tukey-Kramer test, $p<0.05$ for each line). Ht31(16) mice eventually learned the platform position, as reflected by their latencies on the last day of training ( post hoc Tukey-Kramer test, $p>0.05$ ) (Fig. $6 a$ ) and by the normal spatial preference during a probe trial given the day after the last training trial ( post hoc TukeyKramer test, $p>0.05$ ) (Fig. 6b,c). In contrast, Ht31(1) mice were impaired in their spatial preference during the probe trial, demonstrating that genetic disruption of PKA anchoring is associated with impairments in hippocampus-dependent memory tasks (two-way repeatedmeasures ANOVA, $F_{(6,171)}=2.94 ; p<$ 0.01 ; post hoc Tukey-Kramer test, $p<$ 0.05) (Fig. 6b). Ht31(1) mice also exhibited significantly fewer platform crosses than wild-type littermates (two-way repeated-measures ANOVA, $F_{(6,171)}=$ 3.59; $p<0.01$; post hoc Tukey-Kramer test, $p<0.01$ ) (Fig. $6 c$ ). The memory deficits observed in Ht31(1) mice were reversed when transgene expression was suppressed in adult mice by providing
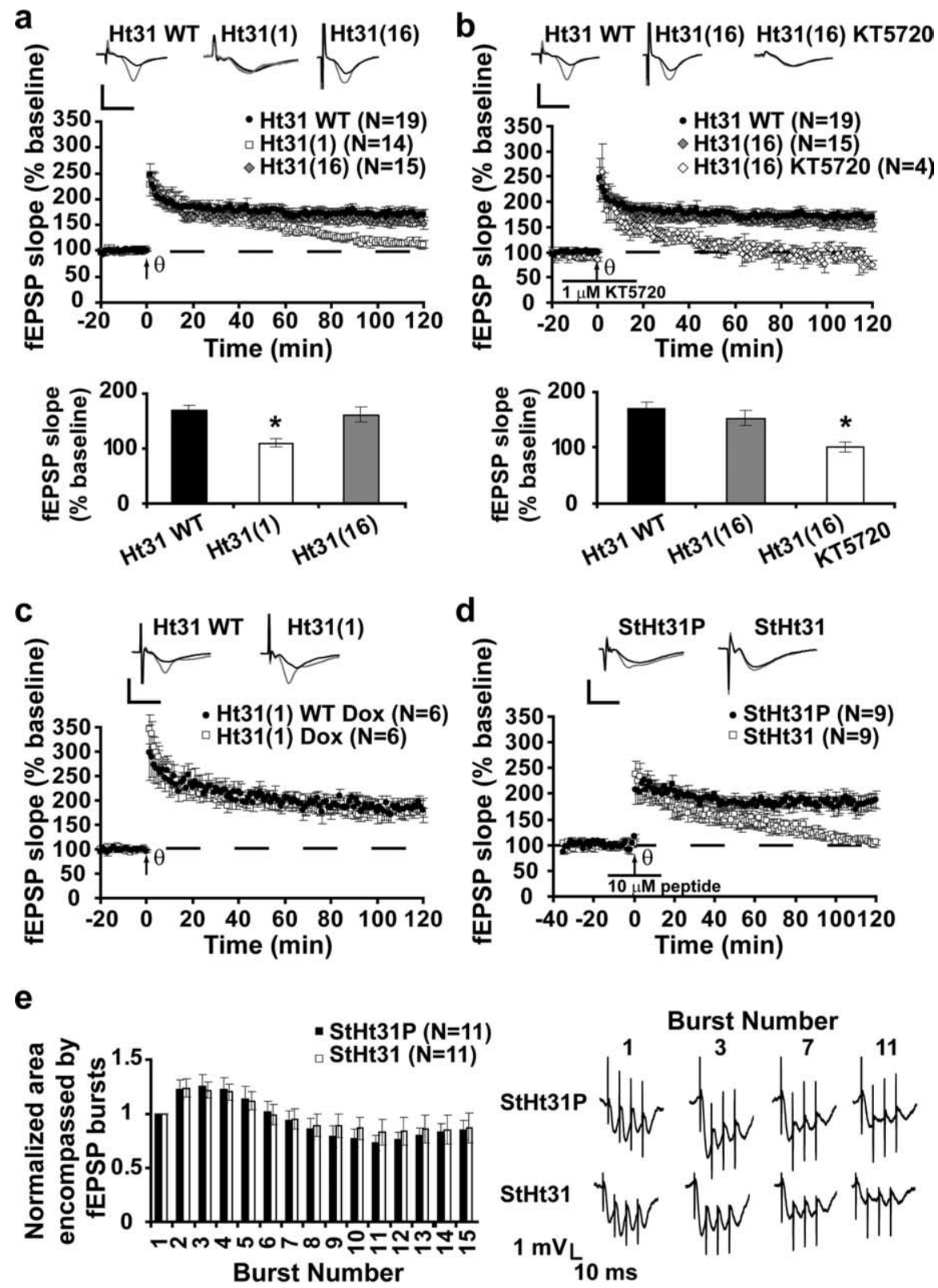

f
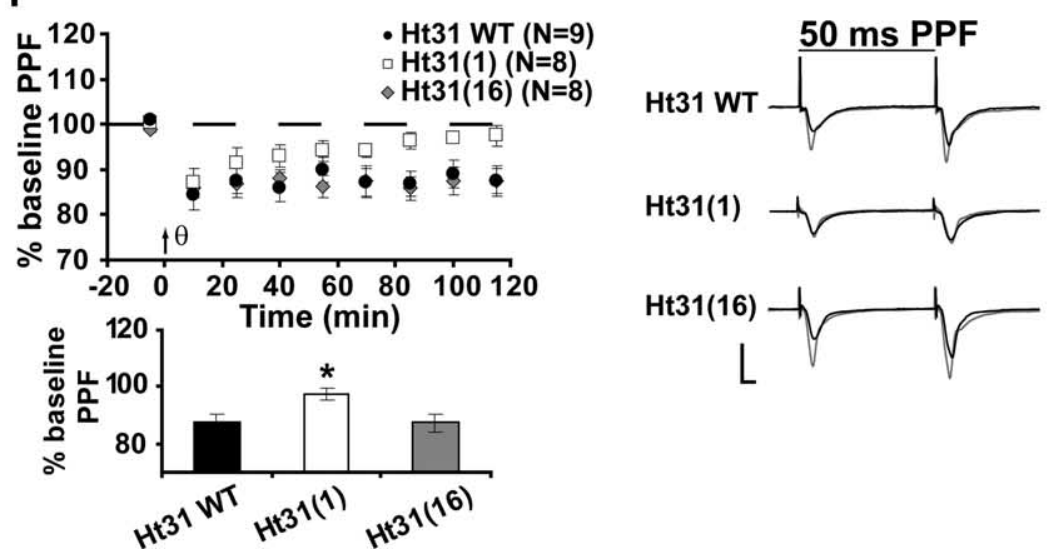

Figure 5. Theta-burst L-LTP requires presynaptic but not postsynaptic PKA anchoring. $\boldsymbol{a}$, LTP induced by a theta-burst stimulation (bursts of four $100 \mathrm{~Hz}$ pulses, $200 \mathrm{~ms}$ apart, $3 \mathrm{~s}$ ) was impaired in slices from $\mathrm{Ht} 31(1)$ animals ( post hoc analysis, ${ }^{*} p<0.05$ ) but not in slices from Ht31(16) animals relative to wild-type littermates ( post hoc analysis, $p>0.05$ ). This demonstrates that theta-burst L-LTP requires presynaptic, but not postsynaptic, anchoring of PKA. The bar graph indicates mean normalized fEPSP slopes at $2 \mathrm{~h}$ after tetanus. $\boldsymbol{b}$, The intact theta-burst L-LTP observed in Ht31(16) mice was not attributable (Figure legend continues.) 
a

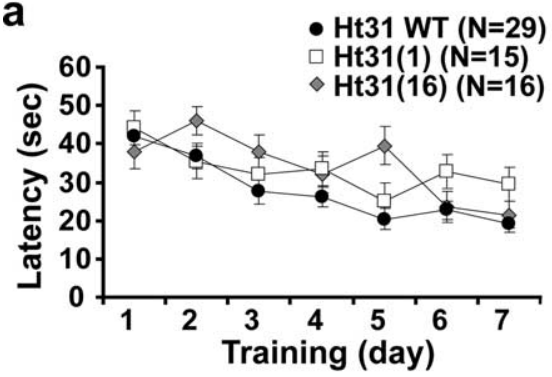

C

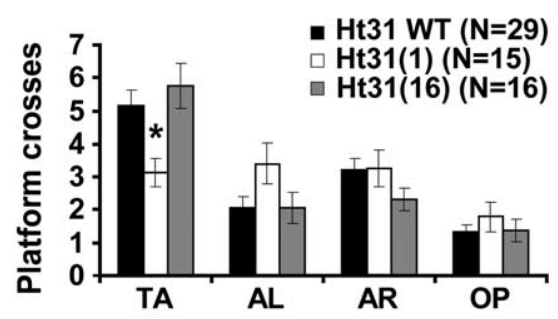

e

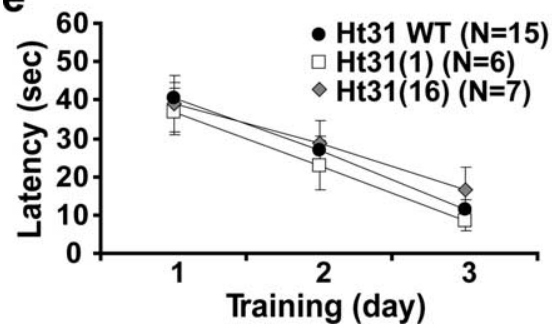

b

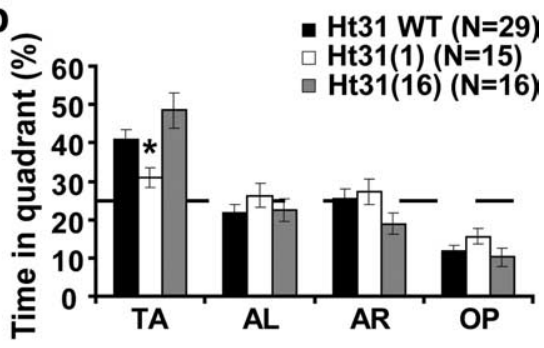

d

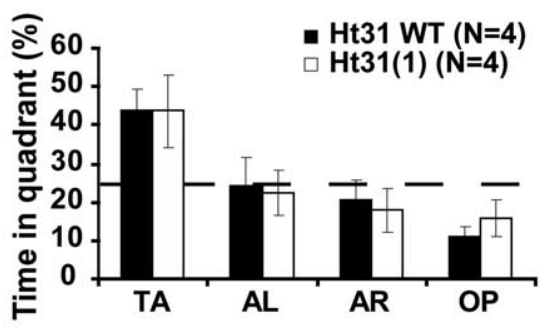

doxycycline $(200 \mathrm{mg} / \mathrm{kg}$ in the mouse diet for 2 weeks), indicating that these deficits in spatial memory were not attributable to developmental or compensatory effects (two-way repeated-measures ANOVA, $F_{(3,18)}=0.118 ; p>0.05$ ) (Fig. 6d). Ht31 transgenic mice were also tested in the visible platform version of the Morris water maze, in which mice learned to locate a platform marked with a visible cue. In this task, both lines of $\mathrm{Ht} 31$ transgenic mice performed as well as wild-type mice (twoway repeated-measures ANOVA, $F_{(4,50)}=$ $0.12 ; p>0.05$ ) (Fig. 6e), suggesting that impairments in spatial memory observed in Ht31(1) transgenic mice in the hiddenplatform version of the water maze are not attributable to visual, motor, or motivational deficits.

\section{Discussion}

AKAPs compartmentalize PKA signaling by forming macromolecular complexes that include phosphatases, phosphodiesterases, and substrates near sites of cAMP synthesis and targets of PKA (Smith and Scott, 2006). In this way, multiple extracellular signals engage spatially distinct pools of kinase. Conditional expression of $\mathrm{Ht} 31$ in excitatory neurons enabled us to disrupt PKA-containing complexes in these cells without altering basal PKA activity. $\mathrm{Ht} 31$ has 300 - to 400 -fold greater binding affinity for type II PKA than type I PKA (Alto et al., 2003), thereby selectively disrupting anchoring of type II PKA. Hippocampal slices from $\mathrm{Ht} 31$ transgenic mice exhibited deficits in long-lasting forms of LTP (L-LTP), without impairing E-LTP or basal synaptic transmission. Behavioral studies of $\mathrm{Ht} 31$ transgenic mice revealed a dissociation of impairments in 6. Impairments in spatial learning and memory in $\mathrm{Ht} 31$ transgenic mice. $\boldsymbol{a}$, In the spatial version of the Morris maze, both lines of $\mathrm{Ht} 31$ transgenic mice exhibited impairments in the acquisition of a spatial preference when compared with wild-type littermates ( post hoc analysis, $p<0.01$ ). $\boldsymbol{b}, \boldsymbol{c}, \mathrm{Ht} 31(1)$, but not $\mathrm{Ht} 31(16)$, mice displayed impairments in spatia memory as assessed by time spent in the target quadrant ( post hoc analysis, ${ }^{*} p<0.05 ; \boldsymbol{b}$ ) and by the number of platform crossings during the probe trial ( post hoc analysis, ${ }^{*} p<0.01$; $c$ ). TA, Target; AL, adjacent left; AR, adjacent right; 0P, opposite. Dashed lines indicate 25\%.d, Ht31(1) transgenic mice, in which expression of $\mathrm{Ht} 31$ has been suppressed by treatment with 200 $\mathrm{mg} / \mathrm{kg}$ doxycycline for 2 weeks, did not display impairments in spatial memory in the hidden-platform version of the Morris water maze ( $p>0.05$, comparison to wild types). $\boldsymbol{e}, \mathrm{Ht} 31$ transgenic mice were not significantly different from wild-type littermates in learning the visible version of the water maze $(p>0.05)$. Error bars represent SEM.

\section{$\leftarrow$}

(Figure legend continued.) to a lack of PKA dependence of this form of LTP, because treatment of slices from Ht31(16) mice with a PKA inhibitor, KT5720 (1 $\mu \mathrm{m}$, as indicated by black bar), significantly impaired this form of LTP ( post hoc analysis, ${ }^{*} p<0.05$ ). Ht31 WT and Ht31(16) data were taken from $\boldsymbol{a}$. The bar graph indicates mean normalized fEPSP slopes at $2 \mathrm{~h}$ after tetanus. C, This deficit in theta-burst L-LTP was abolished when Ht31(1) animals were treated with $200 \mathrm{mg} / \mathrm{kg}$ doxycycline in the diet for 2 weeks $(p>0.05)$, demonstrating that this deficit resulted from expression of the $\mathrm{Ht} 31$ transgene. $\boldsymbol{d}$, The deficit in theta-burst L-LTP was phenocopied by the treatment of slices with StHt31 $(10 \mu \mathrm{m})$ but not by treatment with the control peptide StHt31P $(10 \mu \mathrm{M})$, as indicated. L-LTP in the StHt31-treated slices was significantly different from LTP in the StHt31P-treated slices $(p<0.05)$. , Inhibition of PKA anchoring does not alter normal dendritic field responses to theta-burst stimulation. The areas encompassed by fEPSPs during theta-burst stimulations were not significantly different between StHt31- or StHt31P-treated slices $(p>0.05)$. Sample sweeps were obtained from bursts 1,3, 7, and 11.f, During theta-burst L-LTP experiments ( $\boldsymbol{a}$ ), PPF at $50 \mathrm{~ms}$ interpulse interval was examined every $15 \mathrm{~min}$. PPF decreased after theta-burst stimulation and remained reduced throughout the duration of the L-LTP recording for wild-type littermates and Ht31(16) mice. In contrast, PPF returned toward baseline levels in $\mathrm{Ht} 31(1)$ mice ( post hoc analysis, $p<0.05$ ). In sample sweeps for $\boldsymbol{a}-\boldsymbol{d}$, black traces indicate baseline, and gray traces were acquired at $\sim 2 \mathrm{~h}$ after tetanus. Calibration: $5 \mathrm{mV}, 5 \mathrm{~ms}$. In sample sweeps for $\boldsymbol{f}$, black traces indicate PPF taken during pre-LTP baseline, and gray traces indicate PPF taken at $\sim 2 \mathrm{~h}$ after tetanus. Dashed lines indicate baseline. Error bars represent SEM. spatial learning and memory in the Morris water maze, in which expression of $\mathrm{Ht} 31$ in CA1 impaired learning but left spatial memory intact. In contrast, expression of Ht31 in both CA1 and CA3 impaired both spatial learning and memory.

We report here the first demonstration that PKA anchoring in hippocampal neurons is required for long-lasting forms of hippocampal synaptic plasticity and hippocampus-dependent spatial memory. Our data are consistent with our previous study using a membrane-permeable peptide form of Ht31 (Huang et al., 2006) and extend this finding by showing that PKA anchoring is critical in neurons, rather than in other cell types such as glia or inhibitory neurons. They are also consistent with data from Aplysia neurons showing that $\mathrm{Ht} 31$ peptide impairs facilitation at sensory-motor synapses (Liu et al., 2004). Behaviorally, AKAP5 (also known as AKAP75, AKAP79, and AKAP150) levels increase in mouse hippocampal tissue after associative learning (Nijholt et al., 2007), but no studies have previously addressed the behavioral role of PKA anchoring in the hippocampus. Here, we examined two Ht31 transgenic lines, Ht31(1) and Ht31(16). Each transgenic line expressed Ht31 in hippocampal area CA1 at similar levels, but levels of expression of Ht31 were substantially 
higher in area CA3 in $\mathrm{Ht} 31$ (1) mice than in Ht31(16) mice. Interestingly, four-train L-LTP was altered in both lines, whereas L-LTP induced by theta-burst stimuli was impaired only in Ht31 (1) mice. These data demonstrate that at Schaffer collateralCA1 synapses, four-train L-LTP involves PKA anchoring postsynaptically, whereas theta-burst L-LTP recruits a presynaptically anchored pool of PKA. Evidence for a role for presynaptic mechanisms in thetaburst L-LTP comes from work revealing that theta-burst L-LTP, but not L-LTP induced by four $100 \mathrm{~Hz}$ trains, is associated with an increase in presynaptic vesicular release and with the release of BDNF from presynaptic terminals (Zakharenko et al., 2003). Additionally, PPF after theta-burst L-LTP was persistently reduced in wildtype and Ht31(16) mice but only transiently reduced in $\mathrm{Ht} 31$ (1) mice. This provides mechanistic confirmation for a presynaptic role of PKA anchoring in theta-burst L-LTP. Together, our studies with genetic expression of $\mathrm{Ht} 31$ in neurons and pharmacological treatment with a membrane-permeant peptide version of Ht31 (Huang et al., 2006) indicate that PKA anchoring is selectively involved in long-lasting forms of synaptic plasticity at Schaffer collateral-CA1 synapses as measured with field recordings in acute hippocampal slices from adult mice. In dissociated neuronal culture and in hippocampal slices from young animals, experiments using intracellular application of $\mathrm{Ht} 31$ have observed alterations in basal synaptic transmission that resemble long-term depression (Rosenmund et al., 1994; Tavalin et al., 2002; Snyder et al., 2005). Thus, PKA anchoring may play distinct roles at different times during development. Our findings of a selective role for PKA anchoring in L-LTP are consistent with observations of the role of PKA in acute hippocampal slices from adult mice (for review, see Nguyen and Woo, 2003), but our data reveal a novel role for presynaptic anchoring of PKA in CA3 neurons.

Furthermore, and perhaps most interestingly, our data reveal that a disruption of PKA anchoring in area CA3 specifically impairs spatial memory as measured in the Morris water maze, and reveal that both theta-burst L-LTP and spatial memory require the anchoring of PKA in CA3 neurons (summarized in Fig. 7). Thus, theta-burst L-LTP is a potential cellular correlate for this form of spatial memory. However, our data only demonstrate that spatial memory requires PKA anchoring in CA3 neurons, and we cannot definitively assign a role in spatial memory for presynaptically anchored PKA in Schaffer collateral-CA1 synapses. Nevertheless, the relationship between theta-burst L-LTP and spatial memory is intriguing because this type of stimulus resembles the rhythmic hippocampal electrical activity observed during spatial exploration, a component of which is generated by CA3 neurons (Buzsaki, 2002). In this model, the formation of spatial memories requires that hippocampal neurons strengthen synapses in response to bursts of action potentials that come at the theta frequency.
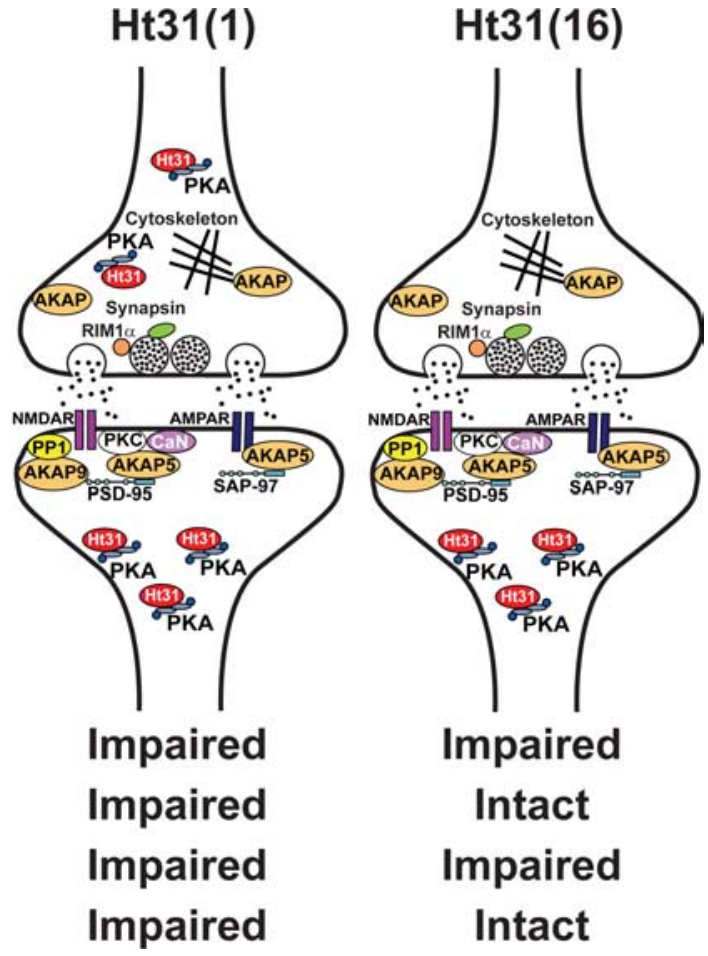

Figure 7. Schematic diagram summarizing the synaptic and behavioral phenotypes resulting from transgenic expression of a blocker of PKA anchoring, Ht31, in hippocampal neurons. Left, In postsynaptic CA1 neurons in wild-type mice, AKAP5 and AKAPS ind PKA to complexes containing AMPA receptors and NMDA receptors. In presynaptic CA3 neurons in wild-type mice, additiona ments in both spatial learning and spatial memory. Right, In Ht31(16) transgenic mice, Ht31 expression in CA1 blocks PKA localization selectively in postsynaptic neurons. In these animals, theta-burst L-LTP and spatial memory were intact, whereas four-train L-LTP and spatial learning were impaired.

Previous work using genetic approaches to define the role of PKA in hippocampal plasticity (for review, see Nguyen and Woo, 2003) has used transgenic mice expressing $R(A B)$, a dominant inhibitory form of the type I regulatory subunit of PKA (Abel et al., 1997), along with pharmacological tools to inhibit or activate the PKA signaling pathway (Woo et al., 2000; Duffy and Nguyen, 2003). Interestingly, this expression of an inhibitor of type I PKA in $\mathrm{R}(\mathrm{AB})$ transgenic mice does not affect theta-burst-induced L-LTP (Woo et al., 2000), a finding that underscores the idea from the present study that type II PKA is specifically required for theta-burst L-LTP. Thus, distinct isoforms of PKA mediate different types of synaptic plasticity (and potentially behavior); future experiments will be needed to address this possibility.

An important future direction is to identify the specific AKAPs in the presynaptic and postsynaptic nerve terminal that map onto particular types of learning, memory, and synaptic plasticity. Much is known about PKA anchoring associated with glutamatergic receptors, such as AMPA and NMDA receptors. AKAP5, for example, anchors PKA close to AMPA receptors via interactions with PSD-95, and this interaction is required for the modulation of glutamatergic receptor currents by PKA (Rosenmund et al., 1994; Tavalin et al., 2002; Snyder et al., 2005). Our current immunoprecipitation experiments have shown that Ht31 expression interferes with a complex that contains type II PKA and PP1, perhaps a complex containing AKAP9 (also called yotiao) and NMDA receptors (Westphal et al., 1999). Recent work suggests that phosphorylation by PKA modulates the calcium permeability of the NMDA receptor (Skeberdis et al., 2006). 
Identifying the specific AKAPs recruited during synaptic plasticity and spatial learning and memory will be challenging. Reagents that block the interactions between PKA and specific AKAPs do not yet exist, and gene knock-out technologies in mice or RNA interference would completely ablate specific AKAPs, disrupting the anchoring of PKA and all other enzymes associated with the ablated AKAP. It is therefore impossible to attribute any observed effects to the mislocalization of only PKA with such manipulations. Thus, what is needed are AKAP-specific probes or genetically modified mice carrying point mutations in the PKA-binding domain of specific AKAPs.

Although much work has focused on the anchoring of PKA in the postsynaptic nerve terminal, little is known about the AKAPs that might localize PKA presynaptically. However, there exist at least two potential targets of PKA in the presynaptic terminal: Rab3-interacting molecule $1 \alpha(\mathrm{RIM} 1 \alpha)$ and synapsin I (Fig. 7). RIM $1 \alpha$ is an active zone-associated protein that is phosphorylated by PKA. Genetic ablation of RIM $1 \alpha$ in mice impairs memory storage (Powell et al., 2004) along with forms of LTP that recruit presynaptic mechanisms (Huang et al., 2005). The expression of $\mathrm{Ht} 31$ in presynaptic neurons may contribute to the observed deficits in theta-burst LTP by blocking a RIM1 $\alpha$ dependent enhancement of release probability. Another substrate linked to presynaptic transmitter release that is modulated by PKA is synapsin I. There is evidence that phosphorylation of synapsin I by PKA plays a major role in adjusting the size of the pool of recycling synaptic vesicles in response to depolarization (Menegon et al., 2006).

Overall, our data reveal specific roles for PKA anchoring in distinct forms of hippocampal learning, memory, and synaptic plasticity. Our findings underscore a requirement for presynaptically anchored PKA in theta-burst L-LTP, but not in L-LTP induced by four trains of high-frequency stimulation. Furthermore, theta-burst L-LTP impairment in transgenic mice expressing Ht31 in CA3 neurons, a blocker of PKA anchoring, was correlated with defective spatial memory. In contrast, when Ht31 expression was predominantly restricted to the CA1 neurons, theta-burst L-LTP and spatial memory were both intact. Fourtrain L-LTP and spatial learning were impaired in both lines of Ht31 mice, suggesting that these two processes predominantly require PKA anchoring in CA1 neurons.

\section{References}

Abel T, Nguyen PV, Barad M, Deuel TA, Kandel ER, Bourtchouladze R (1997) Genetic demonstration of a role for PKA in the late phase of LTP and in hippocampus-based long-term memory. Cell 88:615-626.

Alto NM, Soderling SH, Hoshi N, Langeberg LK, Fayos R, Jennings PA, Scott JD (2003) Bioinformatic design of A-kinase anchoring protein-in silico: a potent and selective peptide antagonist of type II protein kinase A anchoring. Proc Natl Acad Sci USA 100:4445-4450.

Bolshakov VY, Golan H, Kandel ER, Siegelbaum SA (1997) Recruitment of new sites of synaptic transmission during the cAMP-dependent late phase of LTP at CA3-CA1 synapses in the hippocampus. Neuron 19:635-651.

Buzsaki G (2002) Theta oscillations in the hippocampus. Neuron 33:325-340.

Diviani D, Abuin L, Cotecchia S, Pansier L (2004) Anchoring of both PKA and 14-3-3 inhibits the Rho-GEF activity of the AKAP-Lbc signaling complex. EMBO J 23:2811-2820.

Duffy SN, Nguyen PV (2003) Postsynaptic application of a peptide inhibitor of cAMP-dependent protein kinase blocks expression of long-lasting synaptic potentiation in hippocampal neurons. J Neurosci 23:1142-1150.

Fink MA, Zakhary DR, Mackey JA, Desnoyer RW, Apperson-Hansen C, Damron DS, Bond M (2001) AKAP-mediated targeting of protein kinase A regulates contractility in cardiac myocytes. Circ Res 88:291-297.

Frey U, Morris RG (1997) Synaptic tagging and long-term potentiation. Nature 385:533-536.
Frey U, Krug M, Reymann KG, Matthies H (1988) Anisomycin, an inhibitor of protein synthesis, blocks late phases of LTP phenomena in the hippocampal CA1 region in vitro. Brain Res 452:57-65.

Frey U, Huang YY, Kandel ER (1993) Effects of cAMP simulate a late stage of LTP in hippocampal CA1 neurons. Science 260:1661-1664.

Gruart A, Munoz MD, Delgado-Garcia JM (2006) Involvement of the CA3CAl synapse in the acquisition of associative learning in behaving mice. J Neurosci 26:1077-1087.

Huang T, McDonough CB, Abel T (2006) Compartmentalized PKA signaling events are required for synaptic tagging and capture during hippocampal late-phase long-term potentiation. Eur J Cell Biol 85:635-642.

Huang YY, Kandel ER (1994) Recruitment of long-lasting and protein kinase A-dependent long-term potentiation in the CA1 region of hippocampus requires repeated tetanization. Learn Mem 1:74-82.

Huang YY, Zakharenko SS, Schoch S, Kaeser PS, Janz R, Sudhof TC, Siegelbaum SA, Kandel ER (2005) Genetic evidence for a proteinkinase-A-mediated presynaptic component in NMDA-receptordependent forms of long-term synaptic potentiation. Proc Natl Acad Sci USA 102:9365-9370.

Klussmann E, Edemir B, Pepperle B, Tamma G, Henn V, Klauschenz E, Hundsrucker C, Maric K, Rosenthal W (2001) Ht31: the first protein kinase $\mathrm{A}$ anchoring protein to integrate protein kinase $\mathrm{A}$ and Rho signaling. FEBS Lett 507:264-268.

Lattal KM, Mullen MT, Abel T (2003) Extinction, renewal, and spontaneous recovery of a spatial preference in the water maze. Behav Neurosci 117:1017-1028.

Lester LB, Langeberg LK, Scott JD (1997) Anchoring of protein kinase A facilitates hormone-mediated insulin secretion. Proc Natl Acad Sci USA 94:14942-14947.

Liu J, Hu JY, Schacher S, Schwartz JH (2004) The two regulatory subunits of Aplysia cAMP-dependent protein kinase mediate distinct functions in producing synaptic plasticity. J Neurosci 24:2465-2474.

Lynch G, Larson J, Kelso S, Barrionuevo G, Schottler F (1983) Intracellular injections of EGTA block induction of hippocampal long-term potentiation. Nature 305:719-721.

Lynch MA (2004) Long-term potentiation and memory. Physiol Rev 84:87-136.

Malenka RC, Nicoll RA (1999) Long-term potentiation-a decade of progress? Science 285:1870-1874.

Martin SJ, Grimwood PD, Morris RG (2000) Synaptic plasticity and memory: an evaluation of the hypothesis. Annu Rev Neurosci 23:649-711.

Matthies H, Frey U, Reymann K, Krug M, Jork R, Schroeder H (1990) Different mechanisms and multiple stages of LTP. Adv Exp Med Biol 268:359-368

Mayford M, Bach ME, Huang YY, Wang L, Hawkins RD, Kandel ER (1996) Control of memory formation through regulated expression of a CaMKII transgene. Science 274:1678-1683.

Menegon A, Bonanomi D, Albertinazzi C, Lotti F, Ferrari G, Kao H-T, Benfenati F, Baldelli P, Valtorta F (2006) Protein kinase A-mediated synapsin I phosphorylation is a central modulator of $\mathrm{Ca}^{2+}$-dependent synaptic activity. J Neurosci 26:11670-11681.

Moita MA, Lamprecht R, Nader K, LeDoux JE (2002) A-kinase anchoring proteins in amygdala are involved in auditory fear memory. Nat Neurosci 5:837-838.

Nguyen PV, Woo NH (2003) Regulation of hippocampal synaptic plasticity by cyclic AMP-dependent protein kinases. Prog Neurobiol 71:401-437.

Nguyen PV, Abel T, Kandel ER (1994) Requirement of a critical period of transcription for induction of a late phase of LTP. Science 265:1104-1107.

Nijholt IM, Ostroveanu A, de Bruyn M, Luiten PGM, Eisel ULM, Van der Zee EA (2007) Both exposure to a novel context and associative learning induce an upregulation of AKAP150 protein in mouse hippocampus. Neurobiol Learn Mem 87:693-696.

Powell CM, Schoch S, Monteggia L, Barrot M, Matos MF, Feldmann N, Sudhof TC, Nestler EJ (2004) The presynaptic active zone protein RIMlalpha is critical for normal learning and memory. Neuron 42:143-153.

Reymann KG, Frey JU (2007) The late maintenance of hippocampal LTP: requirements, phases, "synaptic tagging," "late-associativity" and implications. Neuropharmacology 52:24-40.

Rosenmund C, Carr DW, Bergeson SE, Nilaver G, Scott JD, Westbrook GL (1994) Anchoring of protein kinase A is required for modulation of AMPA/kainate receptors on hippocampal neurons. Nature 368:853-856. 
Sajikumar S, Navakkode S, Frey JU (2007) Identification of compartmentand process-specific molecules required for "synaptic tagging" during long-term potentiation and long-term depression in hippocampal CA1. J Neurosci 27:5068-5080.

Schenk F, Morris RG (1985) Dissociation between components of spatial memory in rats after recovery from the effects of retrohippocampal lesions. Exp Brain Res 58:11-28.

Schmitt JM, Guire ES, Saneyoshi T, Soderling TR (2005) Calmodulindependent kinase kinase/calmodulin kinase I activity gates extracellularregulated kinase-dependent long-term potentiation. J Neurosci 25:1281-1290.

Schulz PE, Cook EP, Johnston D (1994) Changes in paired-pulse facilitation suggest presynaptic involvement in long-term potentiation. J Neurosci 14:5325-5337.

Schulz PE, Cook EP, Johnston D (1995) Using paired-pulse facilitation to probe the mechanisms for long-term potentiation (LTP). J Physiol (Paris) 89:3-9.

Skalhegg BS, Tasken K (2000) Specificity in the cAMP/PKA signaling pathway. Differential expression, regulation, and subcellular localization of subunits of PKA. Front Biosci 5:D678-D693.

Skeberdis VA, Chevaleyre V, Lau CG, Goldberg JH, Pettit DL, Suadicani SO, Lin Y, Bennett MV, Yuste R, Castillo PE, Zukin RS (2006) Protein kinase A regulates calcium permeability of NMDA receptors. Nat Neurosci 9:501-510.

Smith FD, Scott JD (2006) Anchored cAMP signaling: onward and upward-a short history of compartmentalized cAMP signal transduction. Eur J Cell Biol 85:585-592.
Snyder EM, Colledge M, Crozier RA, Chen WS, Scott JD, Bear MF (2005) Role for A kinase-anchoring proteins (AKAPS) in glutamate receptor trafficking and long term synaptic depression. J Biol Chem 280:16962-16968.

Tavalin SJ, Colledge M, Hell JW, Langeberg LK, Huganir RL, Scott JD (2002) Regulation of GluR1 by the A-kinase anchoring protein 79 (AKAP79) signaling complex shares properties with long-term depression. J Neurosci 22:3044-3051.

Vijayaraghavan S, Goueli SA, Davey MP, Carr DW (1997) Protein kinase A-anchoring inhibitor peptides arrest mammalian sperm motility. J Biol Chem 272:4747-4752.

Westphal RS, Tavalin SJ, Lin JW, Alto NM, Fraser ID, Langeberg LK, Sheng M, Scott JD (1999) Regulation of NMDA receptors by an associated phosphatase-kinase signaling complex. Science 285:93-96.

Whitlock JR, Heynen AJ, Shuler MG, Bear MF (2006) Learning induces long-term potentiation in the hippocampus. Science 313:1093-1097.

Woo NH, Duffy SN, Abel T, Nguyen PV (2000) Genetic and pharmacological demonstration of differential recruitment of cAMP-dependent protein kinases by synaptic activity. J Neurophysiol 84:2739-2745.

Young JZ, Nguyen PV (2005) Homosynaptic and heterosynaptic inhibition of synaptic tagging and capture of long-term potentiation by previous synaptic activity. J Neurosci 25:7221-7231.

Zakharenko SS, Patterson SL, Dragatsis I, Zeitlin SO, Siegelbaum SA, Kandel ER, Morozov A (2003) Presynaptic BDNF required for a presynaptic but not postsynaptic component of LTP at hippocampal CA1-CA3 synapses. Neuron 39:975-990. 